\title{
Psicodinâmica do trabalho e riscos de adoecimento no magistério superior
}

CELINA HOFFMANN, ${ }^{I}$ ROSELAINE RUVIARO ZANINI, ${ }^{I I}$ GILNEI LUIZ DE MOURA, ${ }^{I}$ VANIA MEDIANEIRA FLORES COSTA ${ }^{I}$ ¿ EMANUELLY COMORETTO ${ }^{I}$

\section{Introdução}

A ATIVIDADE docente tem sido amplamente impactada por inúmeros fatores que derivam da crescente valorização do trabalho intelectual; nesse aparato incluem-se as mudanças oriundas da reconfiguração do mundo do trabalho em que são incidentes a revolução informacional e as inovações tecnológicas, bem como o contingente de políticas públicas concernentes à expansão e avaliação de desempenho da Educação Superior no país.

A intensificação da atividade docente reflete um novo paradigma de produção e consumo do conhecimento, no qual coexistem demandas permeadas pela chamada "cultura do produtivismo", caracterizada pela aceleração das atividades, alienação, competitividade e individualismo. Nessa perspectiva, inclui-se a concepção mercantilista que a mensuração do desempenho docente adquiriu, acentuando ainda mais a precarização da atividade. Sob esse enfoque Bosi (2007, p.1516) enfatiza: "Nesse 'vale quanto pesa', o próprio docente é 'valorizado' pela inserção na pós-graduação, pelo número de orientações, artigos e livros publicados e, principalmente, pela 'bolsa produtividade em pesquisa' que consegue por méritos próprios".

Ao incorporar tal realidade o trabalho docente legitima o sofrimento que parece ser indissociável à própria existência, articulado sob o prisma da produtividade e desempenho. Dessa forma, as exigências excessivas aliadas à falta de recursos, a burocratização do trabalho, a cultura de avaliação, a falta de tempo para si têm levado ao adoecimento (Pita, 2010). Na visão de Lemos (2005), as pesquisas nacionais apontam, de forma explícita, os diagnósticos clínicos registrados entre os professores, com o aparecimento de tendinites, cervicalgias e cervicobraquialgias, disfonias, porém ainda é incipiente a investigação sobre os fatores desencadeantes dos problemas de saúde. 
Nesse sentido, faz-se pertinente investigar a tríade trabalho, saúde, doença no contexto da docência do magistério superior, cujo adoecimento pode estar associado à incidência de alguns fatores relacionados à organização do trabalho, como ritmo acelerado, ausência de pausas, exigência de produção, e fatores psicossociais como estresse, ansiedade, depressão e, sobretudo, conflitos de relações interpessoais com chefias, colegas e clientes (Dejours; Abdoucheli, 2011).

Sob esse prisma atua a teoria da Psicodinâmica do Trabalho, que do ponto de vista epistemológico, segundo Mendes (2007a), é considerada uma "teoria crítica do trabalho" que confere contribuições para o entendimento do adoecimento e saúde no trabalho. O contato com essa temática impõe o desafio do diálogo entre as diversas áreas do conhecimento, segundo Seligmann-Silva (201 l, p.15): “o convite para pensar uma realidade que não é mais uma realidade compartimentada das ciências contidas em cubículos isolados, mas a ciência multidisciplinar $[\ldots]$ ", e que por sua abrangência torna-se pertinente a diversas áreas do conhecimento.

A autora destaca que o diálogo entre as disciplinas não pressupõe a transformação de médicos do trabalho ou engenheiros de produção em psicólogos ou psicanalistas, mas que o reconhecimento sobre a subjetividade de trabalho para o escopo e a agenda profissional é essencial à condução e entendimento das ações na rotina de trabalho. Diante disso, o presente estudo tem como objetivo analisar os indicadores críticos de adoecimento no trabalho segundo a percepção dos docentes da Universidade Federal de Santa Maria.

\section{Referencial teórico}

A profissão docente é reconhecida por sua elevada relevância social, visto que a sua atuação está diretamente relacionada à formação de profissionais em diversas áreas do conhecimento, disso decorre a importância do trabalho docente, que pode ser vista sob três enfoques: do indivíduo, da instituição de Ensino Superior (IES), e do país.

Em relação ao indivíduo, é considerado elemento fundamental no processo ensino-aprendizagem, cuja atenção e experiência do professor irão influenciar diretamente o destino profissional, conforme enfatizam Koetz et al. ( 2013, p.1022), "Ser professor está relacionado a participar da independência das pessoas, a torná-las mais livres, menos dependentes econômica, política e socialmente $[. .$.$] ", para além de ensinar, contribuem para a formação de cidadãos$ críticos, capazes de discernir sobre as suas escolhas de maneira consciente.

No que condiz à IES, também terá seu desempenho influenciado pela atuação dos professores, não apenas pelo grau de titulação apresentado, mas também pelo relacionamento interpessoal entre colegas e chefias, e iniciativas de articulação de projetos inovadores, qualidade das aulas ministradas, capazes de gerar procura e preferência entre os estudantes, e suscitar promissor destino profissional de seus egressos. E, como resultado desse encadeamento de influências, a profissão docente exerce função primordial, e até mesmo determinística para o 
desenvolvimento socioeconômico de um país, na medida em que é responsável pela formação do contingente de profissionais de todos os setores da economia.

As pesquisas que se dedicam à temática sobre o trabalho do professor universitário e as transformações decorridas na sua trajetória são, predominantemente, de caráter reclamatório, cuja contextualização ocorre sob o prisma histórico-político, que considera como determinantes prejudiciais para o contexto do trabalho docente fatores macroeconômicos como: globalização, mercantilismo e neoliberalismo. Entretanto, entre os estudos recentes, verifica-se considerável interesse, por parte dos pesquisadores, em abordar assuntos referentes à avaliação e mensuração de desempenho docente, sobre os quais não são raras as críticas.

Dentre a relação de estudos, destaca-se a autora Balbachevsky (2007) que desenvolve importante contributo sobre a temática da carreira docente no Ensino Superior, por meio de um comparativo sobre a evolução da relação entre a titulação e carreira docente nas IES brasileiras entre os períodos de início dos anos 1990 e 2000, considerando as condições de inserção profissional do professor universitário. Segundo a autora os resultados identificados apontam para a confirmação da hipótese de que as IES, diante da tendência crescente da homogeneização da titulação entre os professores universitários, perderam a capacidade de discerni-los e recompensá-los, cumulando na desvinculação entre titulação e carreira.

Sobre o prisma da avaliação de desempenho, Ribeiro (2012) desenvolve estudo sobre o impacto da atual política de avaliação, instituída pelo Sistema Nacional de Avaliação da Educação Superior (Sinaes) sobre o trabalho docente. Os resultados apresentados abordam as implicações da avaliação institucional na ressignificação das atividades pertinentes à gestão administrativa e acadêmica das IES públicas e privadas; a autora aponta as mudanças ocorridas na forma de dar aulas e no relacionamento com alunos. Nesse caso, a pesquisa destaca a importância de estudos voltados ao trabalho docente, que relacionem as mudanças ocorridas no mundo do trabalho com o ambiente de trabalho docente: "Essas futuras pesquisas são extremamente necessárias, dada a carência de investigações a esse respeito, para compreendermos as profundas mudanças que se operam no mundo do trabalho e no trabalho docente" (Ribeiro, 2012, p.134).

Com enfoque mais crítico e de maneira enfática, Bosi (2007) discute a precarização do trabalho docente nas instituições de Ensino Superior, no período de 1980 a 2005, e atribui essa condição a fatores como: a flexibilização de contratos de trabalho em instituições privadas; a priorização de aspectos essencialmente quantitativos para a mensuração e avaliação de desempenho docente; as exigências por pontuação mediante realização de uma série de atividades acadêmicas, as quais são diretamente atreladas às gratificações remuneratórias e desenvolvimento na carreira; e o aumento da competitividade entre os professores, provocado pela disputa da assertividade em editais de pesquisa. Na opinião do autor, todos esses fatores contribuem para a chamada "cultura da produtividade" e alienação do trabalho. 
Segundo Bosi (2007, p.1516), a precarização do trabalho docente está relacionada à concepção mercantilista que a mensuração do desempenho docente adquiriu desde que a cultura da produtividade torna a competitividade e o empreendedorismo aspectos essenciais para os critérios de excelência do desempenho docente. Sob esse enfoque o autor considera: "Nesse 'vale quanto pesa', o próprio docente é 'valorizado' pela inserção na pós-graduação, pelo número de orientações, artigos e livros publicados e, principalmente, pela 'bolsa produtividade em pesquisa' que consegue por méritos próprios” (ibidem). Assim, a diferenciação da identidade docente entre os que exibem pontuação elevada no escore da produtividade acadêmica e os demais docentes que não são contemplados em editais de pesquisa reduz o desempenho acadêmico à lógica imposta pelas agências de fomento à pesquisa que, geralmente, são influenciadas pelas demandas de mercado.

De fato, a inclusão nesse sistema opera uma diferenciação entre os docentes de maneira a estimular a conformação de uma "elite" definida como tal pelo desempenho conseguido nos editais de pesquisa, nas bolsas concedidas, nos artigos publicados, enfim, pela pontuação atingida no escore da produtividade acadêmica. Aparentemente, esse docente tende a acreditar que o seu desempenho é excepcional, fruto de algum tipo de genialidade que o distingue de seus pares. Em essência, geralmente passa despercebido que sua suposta genialidade é eleita por critérios definidos pelos interesses do mercado e que, ela mesma, é produto da própria escassez dos recursos que se tornam alvo de disputa. (ibidem, p.1516)

Ainda sobre a questão da precarização, Guimarães et al. (2012) abordam a questão do trabalho docente voluntário como uma proposta de reflexão sobre o tema, na medida em que o considera como uma das formas de tal ocorrência. A pesquisa baseou-se em estudo de caso realizado em uma universidade pública, mediante abordagem qualitativa; os resultados expuseram diversos pontos negativos presentes no contexto de trabalho do docente voluntário, que possui, além de titulação, o patrimônio intelectual construído pela experiência. Diante dos depoimentos coletados, a pesquisa retrata: “[...] situação caótica, em que se desvela a precarização do trabalho docente voluntário [...], nesse sentido, os autores alertam sobre a importância de tomar medidas que modifiquem tal perspectiva" (Guimarães et al., 2012, p.97).

Ainda na perspectiva da avaliação de desempenho docente, mas nesse caso condizente à mensuração quantitativa, Embiruçu et al. (2010) propõem a utilização de um indicador para avaliação do desempenho docente, que, de acordo com os autores, envolve todas as possibilidades de atividades de trabalho. Dessa forma, defendem, por meio de um método essencialmente quantitativo, a utilização desse indicador como instrumento útil para política e gestão acadêmica, sem, no entanto, deixar de considerar as políticas governamentais.

Em pesquisa desenvolvida sobre a avaliação no contexto do trabalho docente, as autoras Nunes e Helfer (2009) realizaram estudo de caso essencialmen- 
te focado no diagnóstico do desempenho docente, como forma de corroborar o processo de avaliação institucional, além da tentativa de formular um conceito de "bom professor" dado pelos docentes e discentes da instituição, tal ação permitiu participação conjunta entre professores e alunos da instituição para a construção do processo avaliativo, apesar de os resultados apontarem para o reconhecimento da construção permanente sobre o tema.

Os autores Rowe e Bastos (2010) apresentam importante contribuição sobre a carreira na perspectiva do magistério superior, pois propuseram relacionar vínculos na profissão docente com o respectivo desempenho na produção acadêmica, visto que foram utilizados instrumentos voltados à mensuração do comprometimento e entrincheiramento na carreira. Segundo os autores, esses termos remetem à " [...] persistência do trabalhador em um curso de ação que delimita a sua ocupação e os investimentos que faz de forma a construir uma trajetória exitosa, tanto no plano pessoal quanto nos resultados que gera para a sociedade" (Rowe; Bastos, 2010, p.1013). Os resultados apontam que quanto mais o docente investe tempo e dinheiro em sua carreira, maior é a sua produção acadêmica. No entanto, os autores ponderam tal resultado, considerando que existe ampla diversidade de fatores preditores da produção acadêmica que não foram considerados no estudo.

Enquanto Palazzo e Gomes (2009), em pesquisa realizada sobre a avaliação do desempenho docente, buscaram analisar se os critérios utilizados para a progressão de carreira que são fixados pela legislação são os mesmos para uma boa avaliação na perspectiva dos alunos, por meio de estudo de caso realizado em uma instituição de Ensino Superior, a pesquisa aponta que a avaliação dada pelos alunos não condiz com os critérios considerados para a progressão de carreira. Dessa forma, entre outras questões levantadas, o estudo sugere que as políticas educacionais levem em consideração aspectos de fundamentação empírica sobre o rendimento de alunos e o desempenho de professores.

Koetz et al. (2013), em estudo realizado sobre a qualidade de vida de docentes do Ensino Superior, buscaram identificar a qualidade de vida de docentes de instituições comunitárias não confessionais do Rio Grande do Sul quanto aos domínios físico, psicológico, social e ambiental. Segundo os autores, "O trabalho do professor envolve criar vínculos sociais, estimular a autonomia e a responsabilidade através de uma atividade teórico-prática, intelectual e administrativa" (Koetz et al., 2013, p.5). Nesse sentido, requer ampla diversidade de competências e habilidades. Os resultados dessa pesquisa apresentam informações passíveis de ponderação, pois apesar de a maior parte dos professores ter indicado uma qualidade de vida classificada como "boa", cerca de $20 \%$ desses profissionais apontaram resultados negativos para qualidade de vida, apesar da boa remuneração e do trabalho que estimula os processos de ensino/aprendizagem.

Percebe-se que há considerável diversidade entre os enfoques dados às pesquisas recentes realizadas sobre o trabalho do docente no âmbito do magis- 
tério superior, porém pode-se verificar a prevalência do tema relacionado à avaliação de desempenho docente. Ao considerar estudos que relacionam assuntos voltados à saúde física e mental, fatores psicossociais e processos de adoecimento, verifica-se ampla discussão sobre a questão que parece ser consenso entre os pesquisadores: a precarização do trabalho docente das IES e a cultura do produtivismo como fatores que permeiam as rotinas de trabalho e colaboram para o adoecimento; o próximo subtítulo trata desse aspecto.

\section{Trajetória da psicopatologia e da psicodinâmica do trabalho}

A corrente de pensamento que trata da psicopatologia do trabalho teve sua origem e sua trajetória marcadas pelos estudos e ideias do autor Christophe Dejours, médico do trabalho, psiquiatra e psicanalista. Atualmente, é considerado um expoente da escola francesa que trata das questões relacionadas à organização do trabalho e suas consequências sobre a saúde do trabalhador (Betiol, 2011). A psicopatologia do trabalho, em seus primórdios, apresentava principal enfoque nas doenças mentais que, supostamente, eram provocadas pelo ambiente de trabalho; essa vertente de investigação produziu importante literatura sobre doenças de trabalhadores que estavam sujeitos à exposição de agentes toxicológicos, que prediz condição inerente a certos postos de trabalho. Nessa vertente, inclui-se a readaptação para o trabalho por meio de oficinas, reinserção profissional e inaptidão a certos postos de trabalho.

Nesse contexto, a partir dos trabalhos produzidos, emergiu importante lacuna de investigação oriunda da negligência dada ao trabalhador e a sua relação no processo de adoecimento, tendo mais ênfase o mapeamento das doenças do que propriamente o trabalhador. A partir dos anos 1970, por conta de motivação e estímulo provocados, em parte, pelos eventos de maio de 68 na França, as pesquisas passaram a atender o surgimento de uma importante necessidade social de investigar as condições psicológicas do trabalho e suas implicações sobre a saúde dos trabalhadores (Betiol, 2011).

A principal contribuição das pesquisas realizadas a partir de então não estava relacionada à identificação de doenças mentais específicas do trabalho, mas sim referia-se à aparição de problemas psíquicos que provocavam uma fragilização que favorecia o aparecimento de doenças do corpo. Dessa forma, o interesse se voltou à identificação de comportamentos estranhos, insólitos ou paradoxais que pudessem ser agrupados a um conjunto de signos característicos com um valor descritivo generalizável a uma categoria profissional, como a realidade de trabalho repetitivo e sob pressão dado a trabalhadores especializados.

A partir disso, teve início a construção de um modelo teórico capaz de abarcar dados empíricos buscando contextualizar o sofrimento no trabalho e as defesas contra a doença. Conforme explicam Dejours e Abdoucheli em artigo elaborado em 1990, intitulado "Itinéraire théorique em psychopathologie du travail" e traduzido em livro coordenado por Betiol (2011, p.122), "Penetramos então em uma problemática que não utiliza mais o esquema causalista: 
renunciamos a ideia de que o comportamento dos trabalhadores fosse determinado pela própria vontade ou pela força das pressões da situação".

De acordo com Seligmann-Silva (2011), a publicação do livro de Dejours intitulado Travail: usure mentale, traduzido e publicado no Brasil sob o título de A loucura do trabalho (Dejours, 1992), causou grande impacto para a temática ligada à psicopatologia do trabalho. A partir disso, decorreu a construção da escola dejouriana, por meio da participação de diversos especialistas e pesquisadores, que promoveram a articulação em prol da formação da Association pour l'Ouverture du Champ d'Investigation Psichopathologique, instituição que produziu amplo contingente de estudos relacionados à temática, na forma de livros e artigos.

Uma questão importante levantada por Dejours e Abdoucheli (2011), que inicialmente foi vista como um desafio às pesquisas relacionadas à psicopatologia do trabalho, foi a contradição entre o social e o privado, sendo o primeiro relacionado ao ambiente coletivo de trabalho, em que atuam as forças ligadas ao prazer e ao sofrimento, e o segundo relacionado à doença mental que só adquire significado para o indivíduo. As conclusões extraídas a partir disso referem-se ao domínio do privado em detrimento do social, conforme explicam os autores "Ocorre que as reações de defesa são fortemente singularizadas em função do passado, da história e da estrutura de personalidade de cada sujeito" (Dejours; Abdoucheli, 2011, p.123). Isso explica os impeditivos para uma abordagem epidemiológica voltada as doenças mentais relacionadas ao trabalho.

Quanto à metodologia utilizada nos estudos empíricos, tendo em vista a possibilidade de identificação das pressões de trabalho, foram aplicadas entrevistas coletivas; essa técnica permitiu aos trabalhadores deixar transparecer as estratégias defensivas construídas coletivamente, criadas com a finalidade de inibir os efeitos patogênicos do trabalho. Nesse sentido, infere-se que substituição gradual entre o modelo causalista para o modelo dinâmico é reafirmada diante da importância do entendimento da concepção e atuação das estratégias de defesa coletivas e sua dinâmica entre as relações doença/trabalho.

Empiricamente, o mapeamento das pressões de trabalho indicou sua origem na organização do trabalho, que apresenta conceituação subdividida em dois construtos: divisão do trabalho, que consiste na distribuição de tarefas e a prescrição do modo de operar, e divisão de homens, que se refere à distribuição de autonomia, poder e níveis hierárquicos; enquanto as condições de trabalho se contrapõem, conceitualmente, à organização do trabalho, as quais tratam das pressões físicas, químicas e biológicas relacionadas ao posto de trabalho. Dessa forma, as definições de organização do trabalho e condições de trabalho se complementam, na medida em que abrangem aspectos físicos, motivacionais e de relacionamento interpessoal aos trabalhadores:

Se por um lado, as condições de trabalho têm por alvo principalmente o corpo, a organização do trabalho, por outro lado, atua a nível do fun- 
cionamento psíquico. A divisão das tarefas e o modo operatório incitam o sentido e o interesse do trabalho para o sujeito, enquanto a divisão de homens solicita sobretudo as relações entre pessoas e mobiliza os investimentos afetivos, o amor e o ódio, a amizade, a solidariedade e a confiança etc. (Dejours; Abdoucheli, 2011, p.126)

Desde então, a escola de pensamento relacionada à psicopatologia do trabalho adquiriu nova abordagem e evoluiu da preocupação com a identificação de doenças correspondentes à profissão ou ao ambiente de trabalho e passou a voltar-se para uma perspectiva mais abrangente capaz de abarcar a dinâmica das transformações do sofrimento provocado no contexto de trabalho; atualmente ela é denominada Psicodinâmica do trabalho.

Nesse contexto, a Psicodinâmica abarca modelos conceituais que partem da análise da dinâmica que se faz presente nos contextos de trabalho, em que atuam objetividade e subjetividade nas relações e inter-relações de cunho social e político, inerentes às relações de trabalho; assim, o contexto de trabalho pode se tornar lugar de saúde e/ou adoecimento. Basicamente, essa dinâmica pressupõe a atuação da inteligência prática, da personalidade e da cooperação (Mendes, 2007b). Dessa forma, “A Psicopatologia do trabalho [...] passou por um processo de amadurecimento que veio desembocar, recentemente, na proposição de uma disciplina - a Psicodinâmica do Trabalho" (Seligmann-Silva, 201 1, p.18).

Tendo em vista a reconfiguração do mundo do trabalho a partir das novas relações entre as economias mundiais e o capital, mediadas pelas transformações nas formas de produção e consumo, a psicodinâmica do trabalho baseia-se nas análises feitas a partir de interações ocorridas em determinados contextos de trabalho, dessa maneira é fundamental para os estudos relacionados à psicodinâmica do trabalho a consideração das exigências das organizações em relação às atividades dos trabalhadores. Esses aspectos determinam as formas de subjetivação que ocorrerão no contexto do trabalho, que se definem pelas formas de atuação dos trabalhadores em atribuir sentido à sua realidade de trabalho, expresso pelos modos de pensar, sentir e agir de maneira individual ou coletiva (Mendes, 2007b).

De acordo com Mendes (2007a), a partir da década de 1990 a teoria da psicodinâmica do trabalho ficou consolidada como abordagem científica capaz de identificar os efeitos do trabalho sobre a saúde dos trabalhadores, nesse sentido passou a ser crucial entender a subjetividade nas relações de trabalho e como isso é, ou não, eficaz para manutenção de sua saúde laboral. As pesquisas passaram a considerar os pressupostos da psicodinâmica do trabalho com a ocorrência de distúrbios osteomusculares, depressão, alcoolismo, violência moral, banalização do sofrimento, entre outros.

\section{Método}

Este estudo classifica-se como descritivo que visa observar e descrever características de um tema ou fenômeno por meio de registro, análise e correlação 
entre variáveis sem sua manipulação, considerando dados ou fatos da própria realidade (Collis; Hussey, 2005). Utiliza a triangulação metodológica sequencial como forma de minimizar vieses da pesquisa, considerando a complementação dos resultados quantitativos obtidos por meio da abordagem qualitativa (Duffy, 2007).

Quanto à coleta de dados, ocorreu por meio da aplicação do Inventário sobre Trabalho e Riscos de Adoecimento (Itra), que consiste em um instrumento desenvolvido e validado pelos grupos: Estudos e Pesquisas em Ergonomia Aplicada ao Setor Público (ErgoPublic) e Estudos e Pesquisas em Saúde e Trabalho (Gepsat), do Instituto de Psicologia da Universidade de Brasília, e tem como objetivo avaliar algumas dimensões da inter-relação trabalho e processos de subjetivação (Mendes; Ferreira, 2007).

$\mathrm{O}$ instrumento de pesquisa subdivide-se em: a) Escala de Avaliação do Contexto do Trabalho (EACT) formada pelos fatores, organização do trabalho, relações socioprofissionais e condições de trabalho; b) Escala de Custo Humano do Trabalho (ECHT), formada pelos fatores custo afetivo, custo cognitivo, custo físico; c) Escala de Indicadores Prazer Sofrimento no Trabalho (EIPST), formada pelos fatores, liberdade de expressão, realização profissional, esgotamento profissional e falta de reconhecimento; d) Escala de Avaliação dos Danos Relacionados ao Trabalho (EADRT), formada pelos fatores danos sociais, danos psicológicos, e danos físicos, conforme mostra a Figura 1.

Figura 1 - Descrição do instrumento de pesquisa Itra

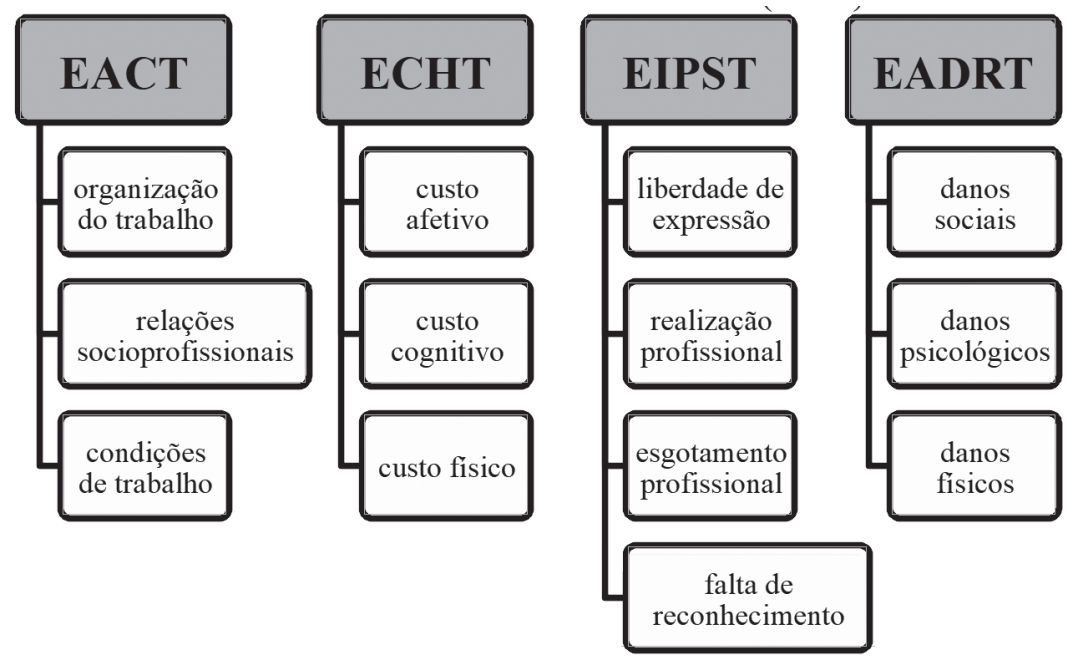

Fonte: Elaborado com base em Mendes e Ferreira (2007).

O envio do instrumento de pesquisa ocorreu por via Google docs a 1.539 docentes da Universidade Federal de Santa Maria, tendo sido obtidas 251 respostas. As áreas de conhecimento com maiores participações foram: Ciências Exatas e da Terra, Ciências Sociais e Aplicadas, Ciências da Saúde, Engenharias. 
A partir disso, foram entrevistados dois docentes (homem e mulher) de cada área de conhecimento que mais tiveram participação na pesquisa: Ciências Exatas e da Terra; Ciências Sociais e Aplicadas; Ciências da Saúde; Engenharias. Buscou-se, assim, complementar os resultados quantitativos com as entrevistas realizadas.

Esta pesquisa foi aprovada sob o número do parecer 494.042, emitido pelo Comitê de Ética em Pesquisa da Universidade Federal de Santa Maria, que é responsável pela avaliação e acompanhamento dos aspectos éticos de todas as pesquisas envolvendo seres humanos, buscando atender os princípios e requisitos condizentes à ética em pesquisa.

Quanto à análise dos dados, no intuito de viabilizar as demais análises estatísticas, fez-se necessária adaptação do banco de dados original, para que, ao invés da utilização dos valores de médias individuais, pudessem ser utilizadas variáveis quantitativas que permitissem a legitimidade dos resultados, por isso foram utilizados os somatórios das respostas de cada um dos sujeitos.

Com a finalidade de verificar a consistência interna dos fatores das escalas que compõem o Itra, foi utilizado o coeficiente Alfa $(\alpha)$ de Cronbach para o contexto de análise que corresponde à Universidade Federal de Santa Maria (UFSM). Em termos de análise para verificar o grau de associação entre os fatores componentes das escalas do Itra foi realizada a correlação de Spearman, visto que, por tratar-se de variáveis qualitativas, os dados não obedecem a uma distribuição normal e, por isso, os métodos relacionados mostraram-se adequados. Além disso, buscou-se identificar perfis com características comuns a cada um dos resultados encontrados pelos fatores do Itra; para isso, foram considerados gênero, faixa etária e estado civil.

\section{Resultados}

Quanto à consistência interna dos fatores das escalas que compõem o Itra, considerando as respostas dos docentes da UFSM, mostrou-se satisfatória, conforme os valores de Alfa de Cronbach identificados: EACT $(0,73)$, ECHT $(0,68)$, EIPST $(0,81)$, EDRT $(0,80)$; tendo em vista a complexidade das questões que o instrumento se propõe a mensurar e o intervalo de valores possíveis de 0 a 1 , o instrumento de coleta Itra mostrou-se adequado para o público da pesquisa em questão, sendo o Alfa de Cronbach geral de 0,76.

É importante compreender o perfil dos docentes participantes de acordo com os níveis de avaliação atribuídos por eles. A Tabela 1 reúne os maiores percentuais encontrados para avaliação em nível satisfatório, crítico ou grave, pertinentes aos fatores que compõem o Itra, em que foram relacionados os grupos quanto a gênero (masculino e feminino), estado civil (casado e solteiro) e idade, considerando dois grupos: docentes com menos ou mais de 41 anos, partindo da premissa de que essa faixa etária corresponde ao principal marco da maturidade profissional. 
Nessa perspectiva, destaca-se que o perfil dos docentes que avaliaram em nível grave o custo cognitivo é formado predominantemente por mulheres $(58 \%)$, solteiras $(57 \%)$ de todas as idades, visto que ambos os grupos de faixa etária apresentaram avaliação grave. Sugere-se uma hipótese explicativa para esse resultado, que consiste na ideia de que as mulheres solteiras sejam mais engajadas no trabalho, a ponto de perceberem maior custo cognitivo nas atividades que executam.

Nesse sentido, as falas das entrevistadas reafirmam essa perspectiva:

"[...] eu percebi o quanto eu estava ficando, o quanto eu estava totalmente imersa e envolvida quando eu comecei a ter medo de abrir os meus e-mails, eu comecei a ter medo, pânico de abrir os meus e-mails, porque cada vez que eu abria eu tinha demandas pra amanhã tem que entregar tal relatório, depois de amanhã tu tem reunião lá fora no campus com a comissão tal, e isso me deixava angustiada [...]."

"[...] com o tempo as coisas vão se acumulando e realmente tem dias que pesa. Como eu te disse tem vezes que tu tem três, quatro bancas em uma semana, tu tem que levar trabalho pra casa, tu passa o final de semana lendo e a semana inteira em banca, em reunião. Chega no outro final de semana tu tá exausta, tu não quer nem enxergar computador na tua frente".

De acordo com Mendes (2007b), a centralidade do trabalho propicia realização profissional aos sujeitos, ao passo que os submete à lógica de produção imposta pela organização do trabalho. Além disso, o trabalho colabora para construção da identidade, na medida em que o sujeito se afirma perante ele mesmo e os demais.

O fator esgotamento profissional também evidenciou maior sofrimento das mulheres (44\%) em relação aos homens, sendo responsáveis pela avaliação em nível crítico, na medida em que para os homens esse fator apresentou avaliação em nível satisfatório (40\%). O fato de o esgotamento profissional não ter afetado tanto os homens quanto as mulheres pode ser explicado pela eficiência da utilização das estratégias defensivas praticadas por eles. Desse modo, segue a fala de um dos entrevistados:

"Cansaço [...] acho que cansaço sim. Mas por enquanto assim eu não estou indo em psicólogo, psiquiatra e não tomo nenhum tipo de remédio. Pelo que eu sei, eu ainda estou muito bem."

Em contrapartida, segue a fala de uma professora entrevistada:

"Então, assim eu tive esse momento de break, e eu percebi o quanto eu estava ficando, o quanto eu estava totalmente imersa e envolvida quando eu comecei a ter medo de abrir os meus e-mails, eu comecei a ter medo, pânico de abrir os meus e-mails, porque cada vez que eu abria eu tinha demandas pra amanhã tem que entregar tal relatório, depois de amanhã tu tem reunião lá fora no campus com a comissão tal e isso me deixava angustiada $[\ldots] . "$ 
Esse resultado apresenta maior discrepância entre homens e mulheres, devido aos níveis de avaliação opostos. De acordo com Dejours (2001, p.101), "Na ideologia defensiva do cinismo viril, a racionalização pelo econômico é uma forma de domínio simbólico típico dos homens". O autor parte da ideia de coragem viril que no ambiente de trabalho decorre do que chama de "irredutível intrincamento entre virilidade e pressão de trabalho" (ibidem). Nesse sentido, os estudos em psicodinâmica do trabalho afirmam que as mulheres não constroem entre elas, no mundo das mulheres, estratégias coletivas comparáveis às dos homens.

No que condiz ao fator organização do trabalho, que corresponde aos aspectos ligados ao ritmo de trabalho, exigências por desempenho e cumprimento de prazos, esse apresentou maior diferença, em termos percentuais, entre os grupos relacionados ao estado civil, visto que a avaliação se deu em nível crítico, porém em maior número pelo grupo dos solteiros $71 \%$, contra $58 \%$ do grupo dos casados. O resultado denota avaliação crítica do fator organização do trabalho por maior parte dos docentes solteiros em relação aos casados. Isso pode ser explicado pela hipótese de que os solteiros se dedicam com mais exclusividade ao trabalho e, por isso, de certa forma, criam expectativas e percepções distintas sobre a organização do trabalho.

Segundo Dejours (1992, p.24) "Em certas condições emerge um sofrimento que pode ser atribuído ao choque entre uma história individual, portadora de projetos, de esperanças e de desejos e uma organização do trabalho que os ignora". Nesse sentido, a prática de levar trabalho para casa, com atividades em finais de semana, passa a ser rotina na vida dos professores, que chegam a não enxergar outra maneira de corresponder a toda demanda da organização do trabalho, conforme as falas sobre o trabalho na vida particular:

"Às vezes é necessário, eu tento manter longe o final de semana, me dedicar mais em casa e à noite, mas às vezes acumula, por exemplo, uma semana que tu tenha muitas bancas tu acaba levando trabalho pra ler em casa porque tu não dá conta, ou final de semestre muitas provas pra corrigir e tu tem prazo pra digitar nota, prazo pra publicar notas pros alunos verem se vão pegar recuperação ou não [...].”

"Sim, com certeza porque basta você ver que mesmo que a gente não tenha horário fechado, com ponto que nem o funcionário administrativo, mas então tu pensa assim quantos turnos tu te envolve; sabe, tu te envolve em quantos turnos, então é só fazer uma conta rápida, eu me envolvo de manhã aqui, de tarde eu tenho mais orientação e de noite eu fico em casa lendo, preparando e tal, bom são 3 turnos.”

O fator custo afetivo apresentou nível crítico para maioria dos docentes participantes, e diferenciou-os, em termos percentuais, conforme os grupos relacionados à faixa etária, em que os mais jovens com idade inferior a 40 anos foram mais acometidos por esse fator com percentual mais elevado (71\%) em comparação com os docentes com idade superior a 40 anos (59\%). Para os demais, não houve diferença relevante entre os percentuais. 
Entende-se por custo afetivo o dispêndio emocional exigido nas interações socioprofissionais inerentes à atividade. Esse resultado pode ser explicado pelas relações de trabalho deturpadas pelo aumento da competitividade e individualismo em que os docentes encontram-se numa corrida constante em busca de aprimoramento das produções científicas gerando contrariedades vivenciadas na rotina de trabalho.

“[...] na chefia de departamento pra ganhar uma passagem pra ir num congresso ali e não existe critério no departamento pra dar pra aquele professor que produziu mais ou não, então o critério do departamento é mandar um resumo de um artigo, então mando o mesmo, professor que não tem publicação nenhuma, que tem uma carga horária baixa e esse professor acaba sendo privilegiado com o consentimento da chefia e [...]."

"[...] dessa coisa assim de contestação que todo mundo acha que pode contestar, então eu vejo que de um modo geral, talvez a gente esteja passando por uma crise de chefia, o cara que tem um cargo ele não adianta ele é chefe, ele tem que decidir, ele tem que mandar só que hoje é uma contestação assim praticamente assim eu faço se eu quiser, eu contesto tudo e aí fica muito difícil.”

Nesse sentido, entram em jogo a vaidade e o status, que deterioram as relações de trabalho. Além disso, a habilidade em atrair e manter atenção dos alunos em sala de aula exige do docente considerável custo emocional que, de certa forma, não é tão representativo no grupo dos docentes acima de 40 anos, e isso talvez aconteça devido à maturidade na carreira.

O fator referente aos danos físicos chama a atenção pela diferença de percentuais ao considerar a comparação por gênero; apesar de ambos os grupos apresentarem avaliação em nível suportável, sendo o percentual do grupo dos homens bem maior (60\%) do que o percentual de mulheres (34\%). Nesse sentindo, seguem as falas dos entrevistados que reconhecem o efeito da sobrecarga de trabalho na saúde.

"Com certeza, porque eu acho que assim, tudo aquele extra que tu tem que fazer pra manter o teu nível de atividade vai ter algum reflexo."

"Bastante, pressão alta, cansaço, insônia, estresse. Em média eu tomo cin$\mathrm{co}$, seis medicações diárias e todas elas provenientes de estresse no trabalho no passado. Hoje não tenho estresse. Então, pra dormir, pressão alta, colesterol, não lembro todos, mas todos foram do trabalho."

A partir disso, verifica-se maior vulnerabilidade dos docentes em apresentar danos físicos, isso decorre da subutilização de estratégias defensivas e falta de cooperação para enfrentar a exposição aos fatores que causam sofrimento e culminam no adoecimento. Em estudo sobre fatores de risco psicossociais, Serafim et al. (2012) ao citar Guimarães et al. (2012) menciona que os riscos estressores ou demandas de trabalho, estão relacionados aos custos psicológicos e fisiológicos inerente à atividade laboral, como a sobrecarga quantitativa ou o conflito de papéis. Nesse sentido, a disposição e combinação entre estes fatores incidirão consideravelmente na a saúde dos trabalhadores. 
Tabela 1 - Maiores percentuais encontrados para cada fator do Itra-UFSM

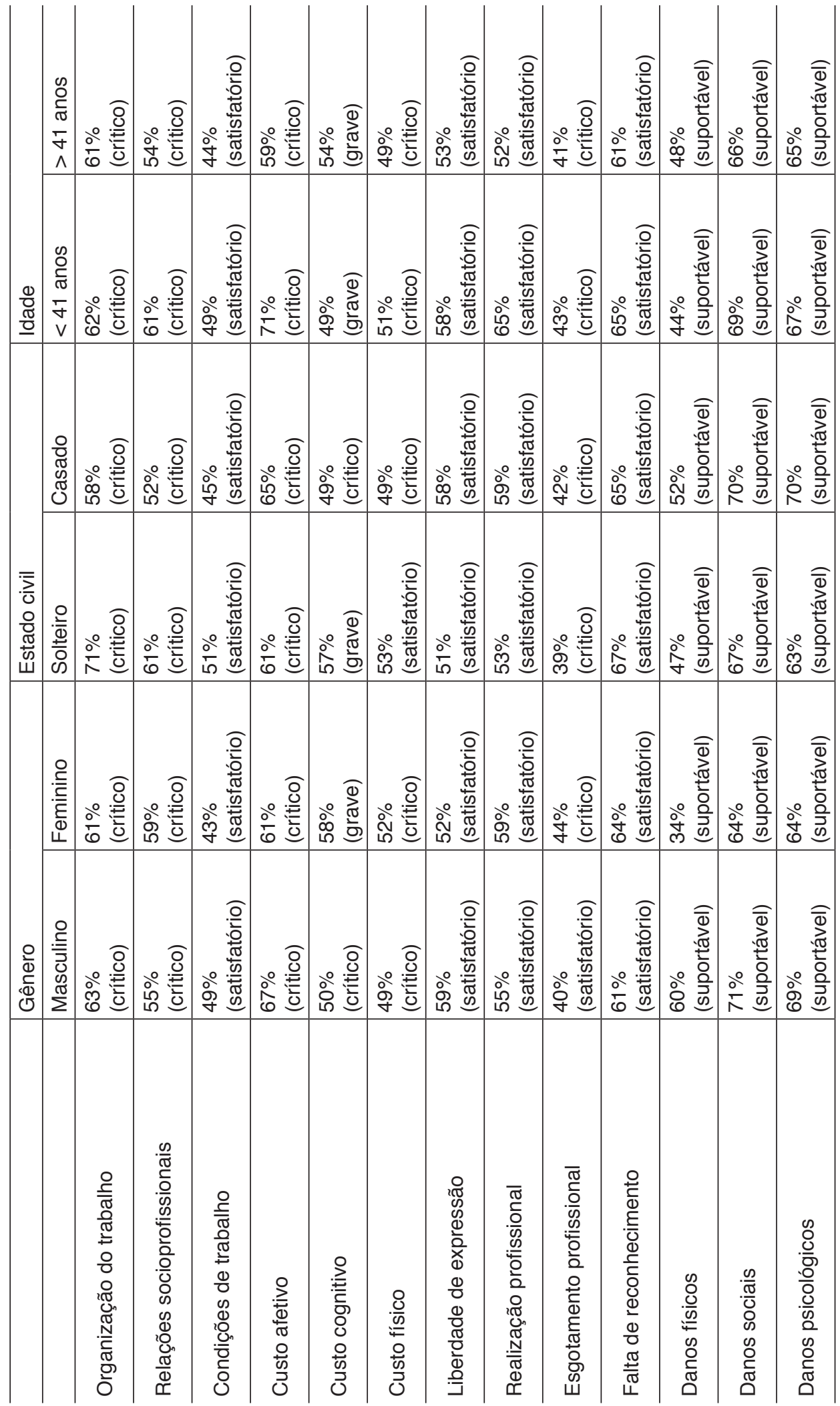


No intuito de complementar os resultados, foram realizados testes não paramétricos para comparação entre grupos. Dessa forma, os grupos condizentes à faixa etária e ao tempo de carreira no magistério superior não apresentaram diferenças significativas. Entretanto, foi possível observar diferença significativa, mediante aplicação do teste Mann-Whitney entre homens e mulheres para os fatores relacionados aos: danos físicos $(\mathrm{p}=0,001)$, danos sociais $(\mathrm{p}=0,01) \mathrm{e}$ custo cognitivo $(p=0,04)$. Nesse sentido, seguem as falas de dois entrevistados que ilustram as diferenças quanto à percepção sobre o trabalho, enquanto a primeira relata exaustão, o segundo aborda a sobrecarga de trabalho como algo natural que está incorporado à sua rotina de trabalho.

"Então, tem dias que eu realmente me sinto assim exausta, exausta fisicamente, emocionalmente, exausta no sentido mais vasto de ser docente, mas eu adoro a docência, o que me motiva a acordar todos os dias é porque eu adoro ser docente, já sou docente há 23 anos, 22 e uns quebrados.”

“[...] então ainda não voltei ao padrão que eu tinha antes da intensidade desse padrão, mas tem muitas coisas, como a gente fala, hoje em dia é uma demanda represada e, mas e algo tão comum que quando eu não faço eu acho estranho."

Esse resultado reafirma a distinção entre homens e mulheres quanto às percepções sobre o trabalho nas perspectivas anteriormente levantadas. Nesse contexto, ao considerar os riscos de adoecimento advindos do trabalho, as mulheres apresentaram maior vulnerabilidade em relação aos homens. Embora a sociedade tenha realizado algumas mudanças favoráveis em relação à participação das mulheres, culturalmente o cuidado com a família recai ao encargo da mulher, e esse aspecto pode ser considerado indicativo para a percepção de sobrecarga acentuada no trabalho.

É relevante, assim, considerar quais fatores das escalas estão associados e que implicações em termos de análise isso pode trazer ao presente estudo. Por meio do Quadro 1, é possível observar os coeficientes de correlação de Spearman significativos e, com esses resultados, é possível verificar quais fatores estão associados. A maior parte dos fatores apresentou correlações significativas; no entanto foram consideradas, para fins de análise, aquelas de intensidade moderadas e fortes.

Destacam-se as correlações fortes positivas, e a direção positiva da correlação pressupõe que níveis crescentes de uma variável estão associados a níveis crescentes de outra variável. Foram identificados com nível de correlação elevado os seguintes fatores: danos psicológicos e danos sociais $(0,76)$; esgotamento profissional e danos psicológicos $(0,75)$; e realização profissional e liberdade de expressão $(0,71)$.

O grau de associação entre danos psicológicos e danos sociais relaciona-se à própria natureza de ambos os construtos, na medida em que os danos psicológicos remetem a um sofrimento intrínseco de caráter individual, enquanto os 
danos sociais representam a deterioração das relações do sujeito com as pessoas de seu convívio familiar e social, expressos por agressividade, isolamento, conflitos, entre outros. A partir disso, pode-se dizer que, apesar de ambos os fatores terem apresentado nível de avaliação suportável, para os docentes participantes da UFSM, os dois fatores estão fortemente associados.

A relação entre esgotamento profissional e danos psicológicos mostrou-se forte e positiva, visto que os itens formadores do fator relacionado ao esgotamento profissional como estresse, sobrecarga, frustração estão fortemente associados aos danos psicológicos que remetem a sentimentos de tristeza, solidão, amargura que refletem estágios dos danos já causados.

Quadro 1 - Coeficientes de correlação de Spearman $(\mathrm{p}<0,05)$ - UFSM

\begin{tabular}{|c|c|c|c|c|c|c|c|c|c|c|c|c|c|}
\hline & 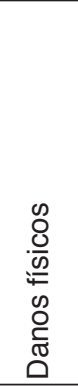 & $\begin{array}{l}\frac{\infty}{\pi} \\
\frac{\pi}{0} \\
0 \\
\infty \\
0 \\
0 \\
\frac{0}{\pi} \\
0\end{array}$ & 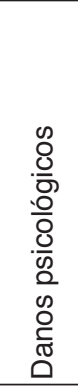 & 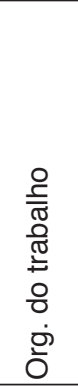 & 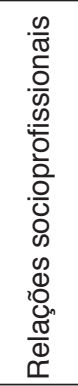 & 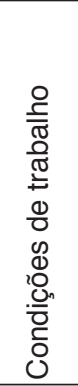 & 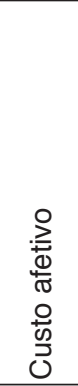 & 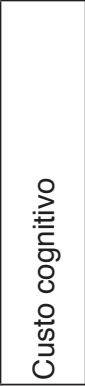 & $\begin{array}{l}0 \\
\frac{0}{00} \\
\frac{0}{0} \\
0 \\
\frac{0}{00} \\
0\end{array}$ & 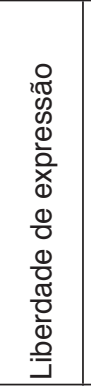 & 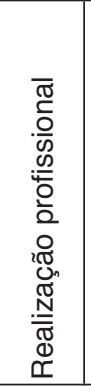 & 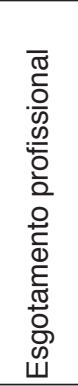 & 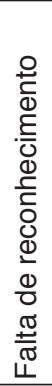 \\
\hline \multicolumn{14}{|l|}{ Danos físicos } \\
\hline Danos sociais & 0,55 & & & & & & & & & & & & \\
\hline $\begin{array}{l}\text { Danos } \\
\text { psicológicos }\end{array}$ & 0,60 & 0,76 & & & & & & & & & & & \\
\hline $\begin{array}{l}\text { Organização do } \\
\text { trabalho }\end{array}$ & 0,48 & & 0,41 & & & & & & & & & & \\
\hline $\begin{array}{l}\text { Relações socio- } \\
\text { profissionais }\end{array}$ & & 0,41 & 0,49 & 0,50 & & & & & & & & & \\
\hline $\begin{array}{l}\text { Condições de } \\
\text { trabalho }\end{array}$ & & & & & 0,53 & & & & & & & & \\
\hline Custo afetivo & & 0,43 & 0,51 & & 0,59 & & & & & & & & \\
\hline Custo cognitivo & & & & 0,41 & & & 0,53 & & & & & & \\
\hline Custo físico & 0,41 & & & & & & & & & & & & \\
\hline $\begin{array}{l}\text { Liberdade de } \\
\text { expressão }\end{array}$ & & & & & $-0,52$ & & & & & & & & \\
\hline $\begin{array}{l}\text { Realização } \\
\text { profissional }\end{array}$ & & & $-0,46$ & & $-0,48$ & & & & & 0,71 & & & \\
\hline $\begin{array}{l}\text { Esgotamento } \\
\text { profissional }\end{array}$ & 0,61 & 0,62 & 0,75 & 0,53 & 0,51 & & 0,57 & 0,41 & & & $-0,46$ & & \\
\hline $\begin{array}{l}\text { Falta de } \\
\text { reconhecimento }\end{array}$ & 0,41 & 0,48 & 0,60 & 0,46 & 0,64 & 0,44 & 0,63 & & & $-0,47$ & $-0,56$ & 0,69 & \\
\hline
\end{tabular}

Fonte: Elaborado pelos autores. 


\section{Considerações finais}

$\mathrm{Na}$ análise da matriz de correlação pôde-se identificar relação de associação moderada entre esgotamento profissional e custo cognitivo $(0,41)$, com a organização do trabalho $(0,53)$ e relações socioprofissionais $(0,51)$. Especificamente no caso das mulheres o esgotamento profissional está fortemente associado à falta de reconhecimento $(0,71)$; nesse sentido, percebe-se que as mulheres são mais impactadas pelos sentimentos de desvalorização, injustiça, desqualificação entre outros.

As diferenças evidenciadas entre homens e mulheres quanto a danos físicos, danos sociais e custo cognitivo reafirmam e corroboram os demais resultados encontrados de maior sofrimento advindo das mulheres no contexto da UFSM. Dessa forma, as características levadas em consideração, como faixa etária e tempo de carreira no magistério superior, mostraram-se irrelevantes para a diferença nos níveis de avaliação.

As mulheres percebem maior impacto dos fatores que provocam sofrimento e adoecimento no trabalho do que os homens, inclusive no que condiz ao custo cognitivo imposto pelo ambiente laboral, com avaliação em nível grave, além de enfrentarem um maior esgotamento profissional, em nível crítico em relação aos homens que apresentaram avaliação em nível satisfatório.

Nesse sentido, descarta-se a ideia de que homens e mulheres submetidos ao mesmo contexto de trabalho, no que se refere ao ambiente do magistério superior da UFSM, apresentem, em mesma proporção, vivências de prazer e sofrimento, e por isso estejam expostos ao mesmo de grau de riscos de adoecimento.

A situação desfavorável percebida pelas mulheres pode ser decorrente da perspectiva da consolidação da mulher no mercado de trabalho e o aumento da competitividade entre elas mesmas e com os homens. Nesse sentido, infere-se a elas a sobrecarga da conciliação entre vida doméstica e profissional, que são atributos agravantes no processo de sofrimento e adoecimento no trabalho. Dessa forma, o papel do gênero deve ser considerado enquanto elemento que promove distinção na percepção, avaliação e gestão dos aspectos que envolvem o trabalho e a vulnerabilidade aos riscos de adoecimento.

Tais resultados, entretanto, podem trazer um viés interpretativo decorrente das características peculiares aos respondentes, tendo em vista que o estudo foi aplicado a uma determinada IES. Além disso, o número de participantes abaixo de $20 \%$ do total da população total representa uma limitação do presente estudo. No entanto, os achados não anulam a necessidade de reflexão por mudanças a em relação aos aspectos que cercam o trabalho do docente do magistério superior.

Assim, deve-se reconhecer a sobrecarga de trabalho a que esses profissionais estão submetidos, seja por razões de legislação federal que lhes impõem parâmetros de avaliação, seja pelas mudanças ocasionadas da relação entre produção de conhecimento e tecnologia que levam ao produtivismo desenfreado. 
Nesse contexto, acredita-se que o trabalho de construção científica do conhecimento deve ser edificante em todas as áreas e que aconteça de forma natural e não mecanizada.

\section{Referências}

BALBACHEVSKY, E. Carreira e contexto institucional no sistema de ensino superior brasileiro. Sociologias, Porto Alegre, n.17, p.158-88, jan./jun. 2007.

BETIOL, M. I. S. (Org.) Psicodinâmica do trabalho: contribuições da escola dejouriana à análise da relação prazer, sofrimento, e trabalho. São Paulo: Atlas, 2011.

BOSI, A. P. A precarização do trabalho docente nas instituiç̃ões de ensino superior do Brasil nesses últimos 25 anos. Educação \& Sociedade, v.28, n.101, p.1503-23, set./dez. 2007.

COLLIS, J.; HUSSEY, R. Pesquisa em administração: um guia prático para estudantes de graduação e pós-graduação. 2.ed. Porto Alegre: Bookmann, 2005.

DEJOURS, C. A loucura do trabalho: estudo de psicopatologia do trabalho. 5.ed. São Paulo: Cortez, 1992.

2001. . A banalização da injustiça social. 4.ed. Rio de Janeiro: Ed. FGV,

. A carga psíquica do trabalho In: BETIOL, M. I. S (Org.) Psicodinâmica do trabalho: contribuições da escola dejouriana à análise da relação prazer, sofrimento e trabalho. São Paulo: Atlas, 2011. p.21-32.

DEJOURS, C.; ABDOUCHELI, E. Itinerário teórico em psicopatologia do trabalho. In: BETIOL, M. I. S. (Org.) Psicodinâmica do trabalho: contribuições da escola dejouriana à análise da relação prazer, sofrimento e trabalho. São Paulo: Atlas, 2011. p.119-43.

DUFFY, M. E. Methodological triangulation: a vehicle for merging quantitative and qualitative research methods. Journal of Nursing Scholarship, v. 19, n.3, p.130-134, 2007.

EMBIRUÇU, M.; FONTES, C. ALMEIDA, L. Um indicador para a avaliação do desempenho docente em Instituições de Ensino Superior. Ensaio: Avaliação em Políticas Públicas da Educação, v. 18, n. 69, p. 795-820, out./dez., 2010.

GUIMARÃES. V. N. et al. Trabalho docente voluntário em uma universidade federal: nova modalidade de trabalho precarizado? Educação em Revista, Belo Horizonte, v.28, n.3, p.77-101, set. 2012.

KOETZ, L. et al. Qualidade de vida de professores de instituições de Ensino Superior Comunitárias do Rio Grande do Sul. Ciência es Saúde Coletiva, v.18, n.4, p.1019-28, 2013.

LEMOS, J. C. Cargas psíquicas no trabalho e processos de saúde em professores universitários. 2005. 147f. Tese (Doutorado em Engenharia de Produção) - Universidade Federal de Santa Catarina. Florianópolis, 2005.

MENDES, M. M. Da psicodinâmica à psicopatologia do trabalho. In: Psicodinâmica do trabalho: teoria, método e pesquisas. São Paulo: All Books Casa do Psicólogo, 2007a. p.29-48. 
MENDES, M. M. Novas formas de organização do trabalho, ação dos trabalhadores e patologia sociais. In: - Psicodinâmica do trabalho: teoria, método e pesquisas. São Paulo: All Books Casa do Psicólogo, 2007b. p.50-9.

MENDES, M. M.; FERREIRA, M. C. Inventário sobre trabalho e riscos de adoecimento - Itra: instrumento auxiliar de diagnóstico de indicadores críticos no trabalho. In: MENDES, M. M. (Org). Psicodinámica do trabalho: teoria, método e pesquisas. São Paulo: All Books Casa do Psicólogo, 2007. p.111-25.

NUNES, A. K.; HELFER, C. L. L. Diagnóstico do Desempenho na Docência da Graduação da Unisc. Avaliação, Campinas, v.14, n.1, p.169-183, mar. 2009.

PALAZZO, J. GOMES, C. A. Plano de carreira e avaliação dos professores: encontros e desencontros. Ensaio: Aval. Pol. Públ. Educ., Rio de Janeiro, v. 17, n. 63, p. 205-234, abr./jun. 2009.

PITA, M. Estresse laboral, assédio moral e burnout marcam produtivismo. Revista ADUSP, p.14-21, set. 2010.

RIBEIRO, E. A. As atuais políticas públicas de avaliação para a educação superior e os impactos na configuração do trabalho docente. Avaliação, Campinas, v.17, n.2, p.299316, jul. 2012.

ROWE, D. E. O; BASTOS, A. V. B. Vínculos com a carreira e produção acadêmica: comparando docentes de IES públicas e privadas. Revista de Administração Contemporânea, Curitiba, v.14, n.6, p.1011 - 1030 nov./dez. 2010.

SELIGMANN-SILVA, E. Da psicopatologia à psicodinâmica do trabalho: marcos de um percurso. In: BETIOL, M. I. S. (Org.) Psicodinâmica do trabalho: contribuições da escola dejouriana à análise da relação prazer, sofrimento, e trabalho. São Paulo: Atlas, 2011. p.13-19.

SERAFIM, A. C. et al. Riscos psicossociais e incapacidade do servidor público: um estudo de caso. Psicologia: Ciência e Profissão, v.32, n.3, p.686-705, 2012. Disponível em < http://dx.doi.org/10.1590/S1414-98932012000300013>

RESUMO - A intensificação da atividade docente reflete um novo paradigma de produção e consumo do conhecimento, no qual coexistem demandas caracterizadas por aceleração das atividades, alienação e competitividade. Nesse sentido, faz-se pertinente investigar a tríade trabalho, saúde, doença no contexto da docência do magistério superior. Diante disso, buscou-se analisar os indicadores críticos de adoecimento no trabalho segundo a percepção dos docentes da Universidade Federal de Santa Maria (RS). Para tanto, realizou-se aplicação do Inventário sobre Trabalho e Riscos de Adoecimento (Itra) e, posteriormente, entrevistas semiestruturadas de caráter complementar, aplicadas aos docentes pertencentes às áreas do conhecimento com maior participação. Destaca-se a identificação de sobrecarga cognitiva em nível grave para as mulheres (58\%) em relação aos homens, com avaliação em nível crítico (50\%), além de maior esgotamento profissional enfrentado por elas, com avaliação em nível crítico (44\%). O teste Mann-Whitney evidenciou diferença significativa entre homens e mulheres quanto aos danos físicos $(\mathrm{p}=0,001)$, danos sociais $(\mathrm{p}=0,01)$ e custo cognitivo $(\mathrm{p}=0,04)$. Dessa forma, o papel do gênero deve ser considerado enquanto elemento que promove distinção na percepção, avaliação e gestão dos aspectos que envolvem o trabalho e a vulnerabilidade aos riscos de adoecimento. 
PALAVRAS-CHAVE: Psicodinâmica do trabalho, Ensino Superior, Adoecimento.

ABSTRACT - The intensification of higher education teaching reflects a new paradigm of production and consumption of knowledge, in which demands characterized by the acceleration of activities, alienation and competitiveness coexist. In this sense, it is relevant to investigate the triad work/health/disease among college faculty. Therefore, we sought to analyze the critical indicators of illness at work, as perceived by the professors of the Federal University of Santa Maria (RS), by applying the Inventory on Work and Risk of Illness (Itra) and, later, semi-structured complementary interviews with faculty belonging to the knowledge areas with the highest participation. We identified serious cognitive overload among women (58\%) compared to men, with evaluation in critical level $(50 \%)$, as well as greater burnout, with evaluation in critical level $(44 \%)$. The Mann-Whitney test revealed significant differences between men and women with regard to physical damage $(\mathrm{p}=0.001)$, social harm $(\mathrm{p}=0.01)$ and cognitive cost $(\mathrm{p}$ $=0.04)$. Thus, the role of gender should be considered as an element that promotes distinctions in perception, assessment and management of aspects involved in work and in vulnerability to risk of illness.

KEYWORDS: Psychodynamics of work, Higher education, Illness.

Celina Hoffmann é doutoranda em Administração na área de Sistemas, Estruturas e Pessoas pela Universidade Federal de Santa Maria (RS).

@ - celina_hoffmann@hotmail.com

Roselaine Ruviaro Zanini é doutora em Epidemiologia pela Universidade Federal do Rio Grande do Sul (RS). Atualmente é professora associada na Universidade Federal de Santa Maria (RS). @-rrzanini@terra.com.br

Gilnei Luiz de Moura é doutor em Administração pela Escola de Economia, Administração e Contabilidade da Universidade de São Paulo. Atualmente é professor adjunto da Universidade Federal de Santa Maria (RS).

@ - mr.gmoura.ufsm@gmail.com

Vânia Medianeira Flores Costa é doutora em Administração pela Universidade Federal da Bahia. Atualmente é professora associada do Departamento de Ciências Administrativas da Universidade Federal de Santa Maria (RS). @ - vania.costa@ufsm.br

Emanuelly Comoretto Machado é graduado em Administração pela Universidade Federal de Santa Maria (RS). @- emanuelly_comoretto@yahoo.com.br

Recebido em 21.7.2015 e aceito em 13.6.2016.

I Programa de Pós-Graduação em Administração, Universidade Federal de Santa Maria, Santa Maria, Rio Grande do Sul, Brasil.

II Programa de Pós-Graduação em Engenharia de Produção, Universidade Federal de Santa Maria, Santa Maria, Rio Grande do Sul, Brasil. 